\title{
BULGARIAN AIR FORCE - CHALLENGES AND PROSPECTS $^{1}$
}

\author{
Major-General Simeon SIMEONOV \\ Commander of the Bulgarian Air Force
}

\begin{abstract}
This introductory article focuses on three main aspects. First, the Air Force missions and tasks in the context of the national and collective security systems are thoroughly explained. Then the author acknowledges and elaborates on the challenges in acquiring the capabilities necessary to accomplish the missions and tasks. The third part looks at the prospects for development of the Air Force in accordance with Plan 2015.
\end{abstract}

Keywords: Air Force Transformation, Security Challenges, Air Force Missions, Force Goals.

The dialogue between experts stands in the base of the public consensus and the process of evolving air power in compliance with the rich national traditions and the new realities related to national security.

At the end of the $\mathrm{XX}^{\text {th }}$ and the beginning of $\mathrm{XXI}^{\text {st }}$ century, under the pressure of globalization, increasing instability in the form of asymmetric threats and scientifictechnical revolution, the world has entered a new phase of development - from postindustrial society into the information era. The world changes its political geography, demography and environment, integrating its multinational economy, eliminating time-space restrictions and uniting security systems under a single flag. Figuratively, the world passes from an environment with a few global threats, with the utmost threat of nuclear self-annihilation, to an environment without such global threats, but with much broader spectrum threats, risks, and challenges.

The parameters of the security environment have changed totally for the past fifteen years. It includes dynamic and hardly foreseen risks and threats, the most serious of which are international terrorism in all its forms, proliferation of weapons of mass destruction, regional conflicts, failed or failing states, organized crime and especially 
illegal trafficking of people, weapons and drugs, natural disasters, accidents and catastrophes, information threats, and social conflicts.

Key factors for the future strategic environment are globalization, increasing complexity of asymmetric war, impact of constantly changing demography and ecology, weak and failing states, radical ideologies, and unresolved conflicts. The security environment generates greater necessity for military response to the global threats. So, to meet adequately the challenges of the dynamic and multidimensional security environment, NATO undertook a deep transformation of its structures and forces and the member states' collective and national security systems.

After the Prague Summit of 2002, the collective and national security systems made a significant progress in their transformation in order to meet the threats and risks in the beginning of $\mathrm{XXI}^{\text {st }}$ century. The main characteristic of the changes in both systems is the rising support to peace and security outside the traditional zone of responsibility: for NATO - outside the Euroatlantic zone, for Bulgaria - establishing a package of military capabilities for participation in joint or coalition operations outside the country's territory. This article puts emphasis on three main aspects:

- Air Force missions and tasks in the context of the national and collective security systems;

- Challenges in acquiring the necessary military capabilities for accomplishment of missions and tasks;

- Prospects for the development of the Bulgarian Air Force in compliance with the long-term plan for development of the Bulgarian Armed Forces, known as Plan 2015.

A decisive step towards the deep transformation of the national security system in the context of the collective security system was the Strategic Defense Review, conducted in 2003-2004. As a result, the National Assembly approved the long-term Force Development Vision, which serves as a basis for the development of the Plan for Organizational Building and Modernization of the Armed Forces till 2015 (Plan 2015), which determined the new missions, tasks, and parameters for the transformation of the Bulgarian military and the Bulgarian Air Force, in particular, and its approval by the Council of Ministers.

We perceive the transformation as a constant process of continuous, deep, and purposeful changes of the Air Force (examined as a system), motivated by the necessity for their adaptation to the new parameters of the strategic environment and establishing integrated capabilities for participation in a wide range of operations. In this sense, the transformation is a response to the challenges of the dynamic and multidimensional security environment. 
The main objectives of Air Force transformation aim at:

- Increasing the capabilities for using information technologies to achieve information superiority and to function in a network-centric environment;

- Shortening the decision cycle and increasing the effectiveness of decisions;

- Increasing the opportunities for conducting non-traditional (other than war) operations;

- Establishing a new structure of forces based on planning, oriented toward the development of requisite capabilities;

- Increasing the expeditionary capabilities of forces;

- Enhancing command and control;

- Integrating and enhancing the operational compatibility with the NATO forces;

- Fully utilizing the human potential;

- Achieving synergism by joint application of capabilities;

- Wide-ranging civil-military cooperation for integration of all force instruments (civil and military) and in a comprehensive approach to crisis management.

For achieving the transformation goals, we shall focus our efforts to the priorities and use effectively the resources, which we possess.

The results then will be measured by the increase of our capabilities to accomplish missions and tasks, participation in complex and joint operations, where forces shall quickly adapt to the changing operational conditions - from intensive combat actions to military activities for stabilization, post-conflict restoration and peace keeping.

As a result of the technological advances and developments, the Air Force shall acquire the following operational capabilities:

- Combat capability;

- Maneuvers and mobility;

- Strike capabilities, long-range engagement of air, ground, and sea-based targets;

- Expeditionary capabilities;

- Capability to act in a network environment;

- Adaptation to the entire range of potential operations;

- Integrated logistics support. 
The advanced technological developments will provide operational superiority of the Air Force during operations.

In the context of the national security strategy, the main AF mission is - jointly with the other services of the armed forces - to guarantee air superiority, security, and independence of the country. This mission is accomplished in the collective security and defense system (NATO) through development of operational capabilities to accomplish the following main missions and tasks:

Mission "Defense" (in the context of Article 5 of The Washington Treaty)

- Participation in the defense of the national territory;

- Participation of the air component in collective defense operations beyond the national territory.

Mission "Support of the International Peace and Security" (out of context of Article 5 of The Washington Treaty)

- Participation in combined crisis response operations beyond the national territory.

- Participation in combined and joint operations to guarantee peace and security.

- Participation in international military cooperation and in multinational and bilateral formations.

- Participation in arms control and countermeasures against the proliferation of weapons of mass destruction and in international humanitarian operations.

Mission "Contribution to the National Peace and Security in Peacetime"

- Participation in the surveillance, control, and defense of the air space and, together with the other types of armed forces, of the national territory and sea space.

- Ground-base air defense of strategic sites.

- Participation in the fight against terrorism, organized crime and trafficking in drugs, people and arms.

- Protection and support of the population in time of disasters and catastrophes.

- Search and rescue operations.

- Support of the normal functioning of state agencies and institutions.

- Participation in preparing the infrastructure for response in case of crisis and environmental protection - provision of support to military contingents as a host-country and environmental protection. 
During combat and crisis response operations, according to its operational characteristics and capabilities, the Air Forces perform specific tasks for:

- Gaining and preserving air superiority in the operational zone.

- Providing air defense of troops and sites on national territory.

- Isolation of the operational area.

- Close air support to the Land Forces, the Navy, and the special formations of the Ministry of the Interior.

- Special actions for support of other services and branches of the armed forces (air reconnaissance and observation; electronic warfare; air transport; airborne landing; combat search and rescue; air control and targeting; air-medical evacuation; support to Special Operations Forces).

To accomplish the defense missions and tasks, the Air Force establishes and supports effective, combat, multifunctional, modular, mobile and interoperable formations with the following operational capabilities:

- Command and Control System, capable to operate in a network environment and to provide superiority in the decision-making process.

- The Airspace Surveillance and Control System is built as "a system of systems" with the following component systems: surveillance and recognition system, fighter coverage system, air defense coverage system, active resource management system and logistics support system.

- Air Reconnaissance Forces - surveillance, patrolling, protection, and defense of the national territory and naval spaces in real time.

- Expeditionary Forces for participation in joint multinational operations, with capabilities for joint deployment, maneuver and support, precision targeting and information superiority.

- Immediate Response Forces on the territory of the country for countering terrorism, protection of the people in cases of disasters, accidents and catastrophes and participation in relief operations.

- Protection Forces of the territory of the country or of an allied country in the collective defense system in all conditions.

- Integral Logistics Forces - protection, education, training, and mobilization of units for Air Force operational deployment.

The Air Force faces a number of challenges and risks in the process of acquiring the necessary operational capabilities.

First, these are the challenges related to the deployable forces and the NATO command forces (Air Policing). The risks connected with these capabilities are low to av- 
erage. They come from the inability to abide by the agreements concerning the Armed Forces, the realization of projects for modernization and acquisition of new equipment and armaments due to the lack of sufficient resources for their implementation.

Second, these are the challenges faced in the process of development of the necessary capabilities of the surveillance and control system. The risks regarding the inability to abide by the agreements are low to high due to the restricted number of combat aircraft and air defense complexes, slow processes of regaining of the airworthiness and modernization of the necessary aviation facilities, as well as a slow process of development of a NATO-compatible control, surveillance, and identification system. The additional risks come from the ambiguity related to the acquisition of new multi-role fighters, 3D radars and modernization of the existing air defense complexes.

Third, these are the challenges connected with the development of capabilities for air reconnaissance, surveillance, patrolling, and protection of the state border, national territory and naval spaces in real time. The risks from the inability to abide by the agreements are low to average. In case of inability to acquire aircraft for air patrolling and reconnaissance (this project is not included in Plan 2015), the risks become high.

Fourth, additional risks in the process of acquiring the necessary operational capabilities appear due to the systematic inability to abide by annual financial plans for material provision in the part for the Air Force (especially concerning overhauls of aircraft, provision of spare parts and aggregates) and the lack of financial resources exceeding the existing budget (planned and programmed).

The Air Force transformation and development strategy is included in Plan 2015. In the context of Plan 2015, the Air Force's organizational building and modernization is subdivided into three stages:

- First stage - from January 2005 till December 2007

At that stage, the Air Command and Control system and the Air Force training system are to be reorganized and modernized, achieving readiness to provide a selected few of the declared Forces for the needs of NATO in line with the approved Force Goals. At the end of this phase the Air Force will be fully manned by contract personnel.

- $\quad$ Second stage - from January 2008 till December 2010

During the Second stage, a reorganization of the AF formations is envisaged in line with the schedule for modernization, rearmament, and transformation of the manpower. The rest of the Air Force Deployable forces shall be rendered into readiness. 
- $\quad$ Third stage - from January 2011 till December 2015

This stage is characterized by modernization and rearmament of the Air Force and utilization of surplus weapons and equipment. The Air Force Command and Control shall join a new NATO Air Force Command and Control system (ACCS). The National Air Defense will be fully integrated into a NATO Integrated Air Defense System (NATINADS).

As a result of the accomplishment of Plan 2015, the Air Force will be organizationally structured as follows:

- Air Force Staff - Sofia;

- Aviation Operational Center with ASOC (Air Sovereignty Operations Center) - Sofia;

- Aviation base for multi-role fighters with two squadrons and a single unit for air policing and reconnaissance located at two airports - Graf Ignatievo and Bezmer. The Bezmer Airport is supported as a front base;

- An airbase with two helicopters squadrons (combat and transport) Krumovo;

- An airbase with one aviation squadron for transport aircraft - Vrazdebna;

- GBAD brigade for air defense of land forces and nine sites;

- Radar regiment with 16 mobile radar units (with six radar stations contributing to the NATO Recognized Air Picture).

- Military University of the Air Force with training airbase-one aviation squadron with training aircraft—Dolna Mitropolia;

- Combat and logistics support units.

In accordance with the new Force Goals, the Air Force establishes Deployable and In-Place Forces.

The Deployable Forces are formations with high and low level of readiness, capable to fulfill the whole spectrum of NATO missions on the territory of the Alliance or beyond it, in the context Article 5 of The Washington Treaty or other crises response military or non-military operations. These forces include as follows:

- Expeditionary aviation unit of combat helicopters - four Mi-24 in role "raid on ground targets";

- Expeditionary aviation unit of transport and special helicopters - three Mi-17 (ready till the end of 2006). It is envisaged that until the end of 2007 the existing helicopters will be replaced by "Cougar", two of which will be transport ones and one will be for MEDEVAC; 
- Module for communications and information support of the deployed aviation units;

- Module for nuclear, chemical, and biological reconnaissance;

- Four pairs of front aviation direction determining aircraft;

- Engineering module for support of de-embarkation at airports;

- Module for oil, lubricants, and fuel - middle class.

The In-Place Forces are formations with high and low level of readiness, capable to fulfill tasks in the defense of territorial integrity (independent of and/or within the Collective Defense System), national air sovereignty defense operations within the NATO Integrated Air Defense System, assuring contribution to the national security in peacetime, and countermeasures against potential asymmetric threats. They establish capabilities providing replacement and rotation of the formations from the deployable forces or of these, which are assigned to the European Union forces.

The NATO Command Forces in NATINADS include in their structure a pair (after 2007 - a group) of fighter airplanes and the Air Sovereignty Operations Center (ASOC) from the Air Operational Center (AOC), operationally subordinated to the Combined Air Operations Center (CAOC-7) in Larissa.

According to the EU operations manual, the Air Force can offer a combined helicopter group (two attack and two transport helicopters) for participation in EU-led operations.

The Immediate Response Forces contribute to the accomplishment of the mission "Contribution to the National Security in Peacetime."

The Air Force Command and Control System includes two levels:

- Operational - Bulgarian Air Force HQ with AOC;

- Tactical - airbases' staff, brigades, units and subunits with base (brigade) operational centers, support management posts from the MATSA and command posts (operational centers) of the subunits.

The C2 system of the Air Force is supported by the communications, information, navigation system (CINS) and Radiolocation surveillance and recognition system.

Education and Special Training of the AF cadre will be implemented in the Air Force Academy (cadets - in the university faculties, sergeants - in the professional college, and contract soldiers in the education and qualification centers).

The training of the young pilots shall be accomplished in the approved training center for pilots (including foreign aviation specialists) in line with the standards of NATO and ICAO. The training center is part of the Air Force Academy. 
Further training of the personnel and staffs shall be conducted in the AF units in compliance with the annual training plans.

The enhancement of qualification of personnel shall be implemented through professional courses and post graduate-level specialization course.

Further education of the officers is carried out in the "G.S. Rakovski" Defense and Staff College or other international military colleges and academies.

The Armed Forces Goals and criteria accepted by the NATO members in compliance with the national programs and traditions provide the basis for force training.

The AF Logistics Support is provided through the system for unified logistics of the Bulgarian Army. Logistics priorities are:

- Logistic support during training and participation in the full range of missions and tasks on the territory of the country or abroad;

- Provision of effective and accident-free service and exploitation of weapons and equipment;

- Medical provision of personnel;

- Infrastructure modernization in line with NATO and ICAO standards.

In compliance with the organizational and functional structure of the Air Force, the following weapon systems and equipment shall be fully operational by the end of 2015:

- Multi-role tactical fighters - 20;

- Combat helicopters - 12;

- Transport aircraft - 10;

- Transport helicopters - 18;

- Training aircraft - 18;

- Air patrolling and reconnaissance aircraft - 4;

- GBAD units - 14;

- $\quad 3$ D radar complexes -16 .

We appreciate the importance of the technical advances and innovation for the Air Force development and operation, but within the range of resource capacity of the country. Also, we think that the technological advances should be accompanied by intellectual development, bringing changes in the organization, doctrine, and in the people's way of thinking. Only then the full potential of the Air Force operational capabilities could be achieved. 
We are led by the understanding that the Bulgarian Air Force, together with the other services and NATO forces, has to be joint force capable of performing the full spectrum of missions and military operations of the Alliance.

\section{Notes:}

1 Briefing by the Commander of the Bulgarian Air Force HQ at the international conference organized by AFCEA-Varna, 14-15 March 2006, Park-Hotel "S.Peterburg" - Plovdiv.

Major General SIMEON SIMEONOV is an officer and fighter pilot since 1979 and has served in all command-level positions in the Bulgarian Air Force. In the period 2004-2005 he served as a Chief of Staff of the NATO's Joint Training Center in Poland. Since 2005 he leads the Bulgarian Air Force - first as Chief of Staff and then as a Commander. During the preparation of this volume for publication he was promoted to LIEUTENANT GENERAL. 